\title{
Integration and Performance Investigation of Multilevel Inverter with Half Bridge and Developed H-bridge Configurations
}

\author{
Mahwish Memon \\ Student of Master's in Electrical \\ Engineering \\ Mehran University of Engineering \\ and Technology Jamshoro
}

\author{
Mukhtiar Ahmed Mahar \\ Professor of Electrical Engineering \\ Mehran University of Engineering \\ and Technology Jamshoro
}

\author{
Aneeqa Sattar \\ Student of Master's in Electrical \\ Engineering \\ Mehran University of Engineering \\ and Technology Jamshoro
}

\begin{abstract}
This document introduces a new structure of power switches for Developed H-bridge with half bridge connected in cascade to provide increased of a nine-stepped output voltage inverter. The proposed model requires lesser number of switches and $\mathrm{dc}$ power sources, which results in decreasing the complexity of total cost of inverter. The multi-carrier pulse width modulation (LS-PD-PWM) method is designed to reduce the percentage of (THD) Total harmonic distortion. The output voltage THD is calculated using FFT analysis tool and is found to be $13.97 \%$. The results taken by simulation are validated using MATLAB/SIMULINK software.
\end{abstract}

\section{General Terms}

Multilevel Inverter, Pulse Width Modulation (PWM), Semiconductor switches.

\section{Keywords}

Multilevel Inverter, POD-PWM, Cascaded H-Bridge inverter, MATLAB/Simulink Model.

\section{INTRODUCTION}

In nowadays electric power engineering investigator pay their interest on MLI to get high power quality, lower shift losses and reliable power for many industrial applications. [1] [2]. By using lesser number of DC sources as input with different structures of electronic switches these inverters generate staircase voltage waveform [3] a replacement topology has been planned with lesser number of DC voltage sources and lesser number of power switches. This paper proposes a simulation model for 9 level uneven cascaded Developed h-bridge with half bridge MLI arrangement The output voltage has been taken by utilizing phase opposition disposition arrangement (POD) technique. Review of different MLI topologies has been conducted. The output voltage waveform and THD analysis has been carried out.

The strategies of 3 standard MLI structures are available to generate levels output voltage waveform, i.e., neutral-pointclamped (NPCMLI) or diode clamped (DCMLI), flying capacitor (FCMLI) and cascaded H-bridge (CHBMLI) [4][5]. Multilevel inverters further cascaded arrangement is classified into two arrangements i-e asymmetric and Symmetric. [4][6].

In asymmetric arrangement DC sources are unequal in its $\mathrm{H}$ bridge, whereas in symmetric arrangement DC sources are equal. to output voltage waveform and reduce the THD and switching losses, different modulation methods are implemented. [7][8]
The specific arrangement of switches and modulation technique selection is dependent on the power requirement. Switching techniques are classified into two kinds of i.e., fundamental frequency switching and high frequency switching. [9][10] These techniques include selective harmonic elimination (SHE), phase shift, sinusoidal PWM and space vector [11] Mostly pulse width modulation (PWM) is widely used PWM. Also, divided into phase disposition arrangement (PD), phase opposition disposition arrangement (POD) and alternate phase opposition disposition arrangement (APOD) techniques [12][13].

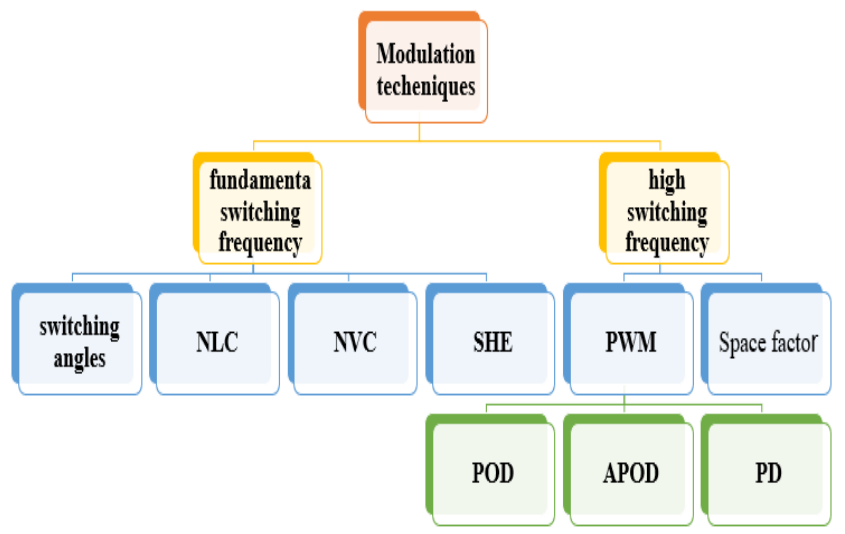

Fig 1: Classification of Modulation Techniques

\section{METHODOLOGY}

For the simulation of proposed model MATLAB/SIMULINK is the software used The THD of the output voltage wave is measured using FFT analysis tool in MATLAB/SIMULINK software.

Parameters for the Proposed simulation model taken are shown in table 1 .

Table 1: Proposed Model Parameters

\begin{tabular}{|l|l|}
\hline Frequency of Sine wave & $50 \mathrm{~Hz}$ \\
\hline Switching frequency of power switches & $1000 \mathrm{~Hz}$ \\
\hline Output voltage levels of Proposed Model & 9 \\
\hline Resistive load & $100 \Omega$ \\
\hline Power Switches & IGBT \\
\hline No. of switches used in Proposed Model & 8 \\
\hline No. of DC voltages & 3 \\
\hline Magnitude of DC voltages & $\mathrm{V}_{1}=\mathrm{V}_{2}=10 \mathrm{~V}$ \\
& $\mathrm{~V}_{3}=5 \mathrm{~V}$ \\
\hline
\end{tabular}




\section{CASCADED CONNECTION OF DEVELOPED H-BRIDGE MLI WITH HALF-BRIDGE CONFIGURATION \\ 3.1 BLOCK DIAGRAM OF PROPOSED TOPOLOGY}

Figure 2 shows the block diagram of proposed model comprise of developed H-bridge MLI in cascaded fashion with half-bridge configuration

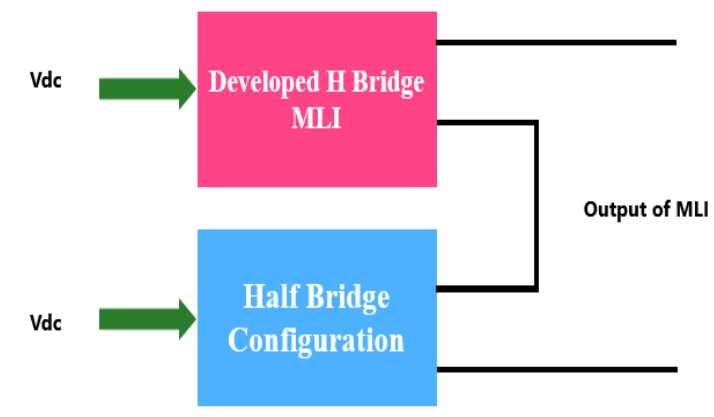

Fig 2: Block Diagram of proposed Model.

\subsection{PROPOSED TOPOLOGY}

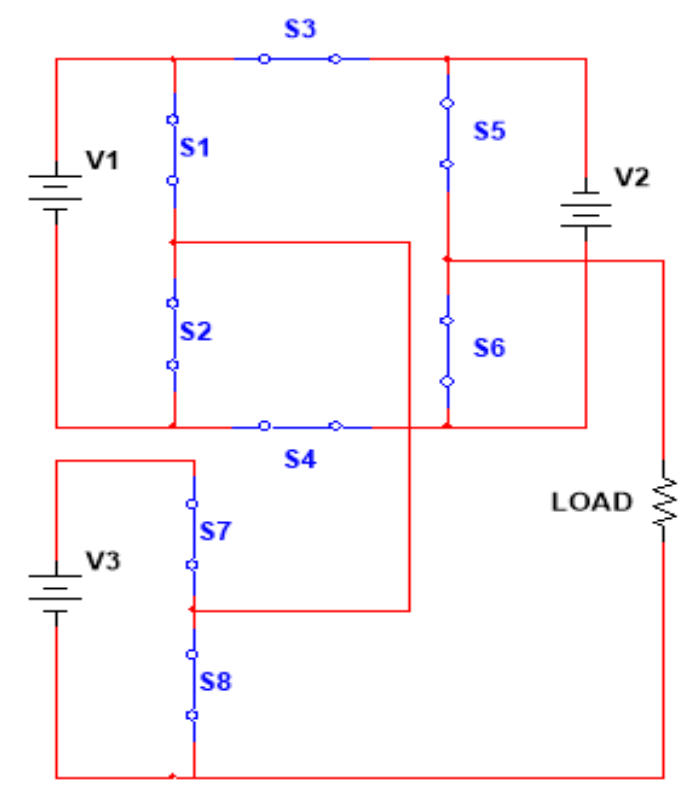

Fig. 3: Proposed Model for Nine-level inverter

Figure 3: shows A developed $\mathrm{H}$-bridge electrical converter is extended by connected single phase half-bridge inverter with separate single Dc source. The main purpose of this series connected half-bridge inverter is to maximize the output voltage levels, reduce harmonic distortion (THD) and enhance power quality [7] [14].

The proposed topologies shown in figure 3 are comprising of by adding two more unidirectional switches and one voltage source DC to the developed H-bridge inverter structure i-e the proposed inverter topology is comprising of eight (8) unidirectional power switches that are (S1, S2, S3, S4, S5, S6, $\mathrm{S} 7, \& \mathrm{~S} 8)$ and three voltage sources DC (V1, V2, \& V3) in this paper the proposed model of inverter is called as cascaded connection of developed $\mathrm{H}$-bridge and half bridge multilevel inverter (DHB-HB-MLI)

In figure 3 the simultaneously turn-on of (S1\& S2) or (S5 \& S6) or (S3 \& S4) and (S7, \& S8) causes voltage source as short circuited i-e to turn on simultaneously of these switches must be avoided.

If the DC sources V1 \& V2 of developed h-bridge inverter are equal in magnitude i-e (2pu) with same polarity and voltage source V3 of Half bridge inverter with magnitude i-e (1pu) then levels of output voltage decrease to five.

If the DC sources V1 \& V2 of developed h-bridge inverter are equal in magnitude i-e(2pu) with change in polarity and DC source V3 of Half bridge inverter with magnitude i-e (1pu) then levels of output voltage increase. i-e total output voltage levels will be nine-levels.

So, polarities of DC sources should be in asymmetric to create Maximum output voltage levels without increasing the quantity of switches. because by only changing the polarities of dc supply the output levels are increased by four levels also cost of proposed model will be less.

The DC sources magnitudes for proposed model of nine-level inverter shown in figure 3 are as follows

$$
\begin{aligned}
& \mathrm{V} 1=2 \mathrm{Vdc} \\
& \mathrm{V} 2=2 \mathrm{Vdc} \\
& \mathrm{V} 3=\mathrm{Vdc}
\end{aligned}
$$

Considering eq $(1,2, \& 3)$ for proposed nine level inverters, generates $0, \pm \mathrm{Vdc}, \pm 2 \mathrm{Vdc}, \pm(3 \mathrm{Vdc}), \pm 4 \mathrm{Vdc}$ at output.

\section{SIMULATION MODEL}

The proposed Model has been modelled in MMATLAB/ SIMULINK software, which is developed by MathWorks Inc. The POWERGUI tool has been used for THD and output voltage analysis.

\subsection{MAIN CIRCUIT}

This simulation model comprises of eight IGBT transistors It incorporates three DC sources of two $10 \mathrm{~V} \&$ one $5 \mathrm{~V}$. As seen in Fig 4.

The proposed model for asymmetric developed H-bridge with Half-bridge MLI comprises of eight IGBTs, and three dc voltage supply shown in Fig.4. To receive the 9-level stepped output, the switches are signaled using POD-PWM technique, according to the switching pattern of IGBT switches the respective operation modes for the proposed model described below.

In $1^{\text {st }}$ mode, $\mathrm{S} 2, \mathrm{~S} 4, \mathrm{~S} 6 \& \mathrm{~S} 7$ switches are triggered to give output V3 (5V).

In $2^{\text {nd }}$ mode, $\mathrm{S} 2, \mathrm{~S} 3, \mathrm{~S} 5 \& \mathrm{~S} 8$ switches are triggered to give output V1 (10V).

In $3^{\text {rd }}$ mode switches $\mathrm{S} 2, \mathrm{~S} 3, \mathrm{~S} 5 \& \mathrm{~S} 7$ are triggered to give output V1+V3 (15V)

In $4^{\text {th }}$ mode, switches S2, S3, S6 \& S8 are triggered to give output V1+V2 (20V)

In $5^{\text {th }}$ mode, switches S2, S3, S6 \& S8 are triggered to give the output $(0 \mathrm{~V})$.

In $6^{\text {th }}$ mode, switches $\mathrm{S} 1, \mathrm{~S} 4, \mathrm{~S} 6 \& \mathrm{~S} 7$ are triggered to give output V3-V1 (-5V)

In $7^{\text {th }}$ mode, switches $\mathrm{S} 2, \mathrm{~S} 3, \mathrm{~S} 4 \& \mathrm{~S} 8$ are triggered to give output -V2 $(-10 \mathrm{~V})$.

In $8^{\text {th }}$ mode, switches $\mathrm{S} 1, \mathrm{~S} 4, \mathrm{~S} 5 \& \mathrm{~S} 7$ are triggered to give output V2+V3-V1 (-15V). 
In $9^{\text {th }}$ mode, switches $\mathrm{S} 1, \mathrm{~S} 4, \mathrm{~S} 5 \& \mathrm{~S} 8$ are triggered to give output -V1-V3 (-20V).

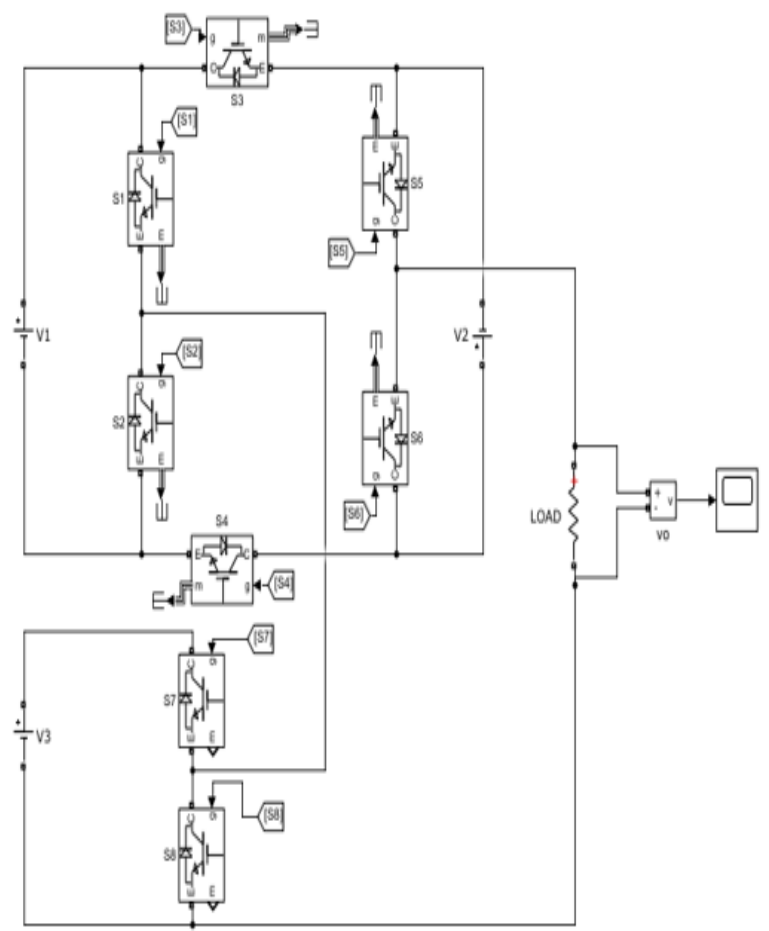

Fig. 4. Simulation Model for 9-level Asymmetric DHB with HB MLI

\subsection{CONTROL CIRCUIT}

The control circuit comprises of several comparators to generate the multicarrier waveform with POD technique. It can be seen in Fig. 5.

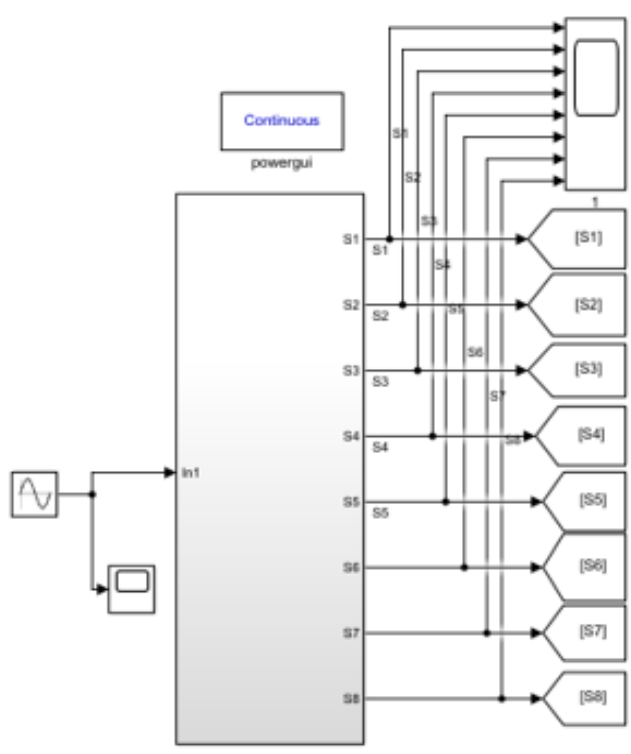

Fig 5: Control circuit of Proposed Model

Multi-carrier based PWM-POD is adopted to produce desired gating signals for power switches. The PWM-POD technique creates sufficient delay to trigger the switches accordingly to generate nine level voltage output waveforms

\section{SIMULATION RESULTS}

Based on proposed topology of cascaded developed h-bridge with half-bridge multilevel inverter (cascaded DHB-HB MLI) as shown in fig 4 has been used for simulation to verify performance of proposed DHB-HB-MLI in generating all output voltage levels (odd \& even).

The proposed topology for cascaded DHB-HB MLI comprises of eight IGBT switches and three DC voltage sources shown in figure 4 to receive nine-level stepped output voltage waveform the switches are signaled by POD-PWM carries technique Each step has a difference of $5 \mathrm{~V}$ as staircase shown in output waveform figure 6 . This simulation is done by the usage of MATLAB/SIMULINK software

The total-harmonic-distortion is found to be $13.97 \%$. THD waveform is shown in Figure 7.

The THD analysis was carried out working on FFT analysis tool of MATLAB/SIMULINK software.

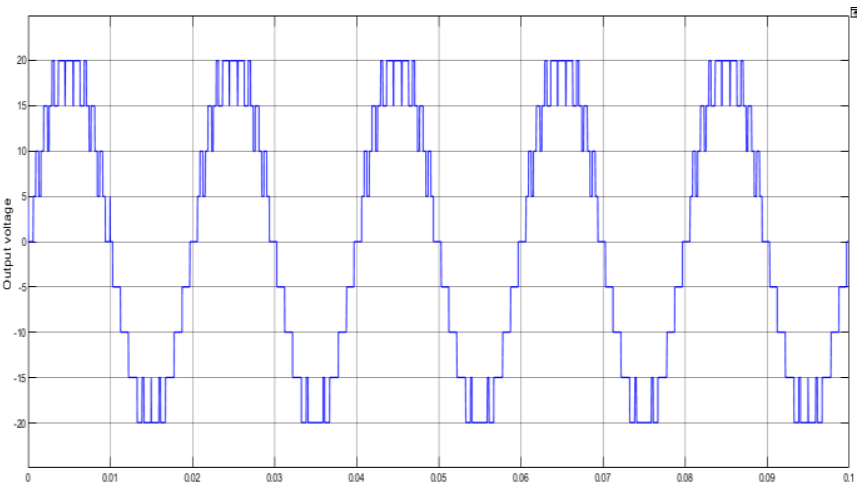

Fig 6: Output Waveform of Nine-level Voltage.

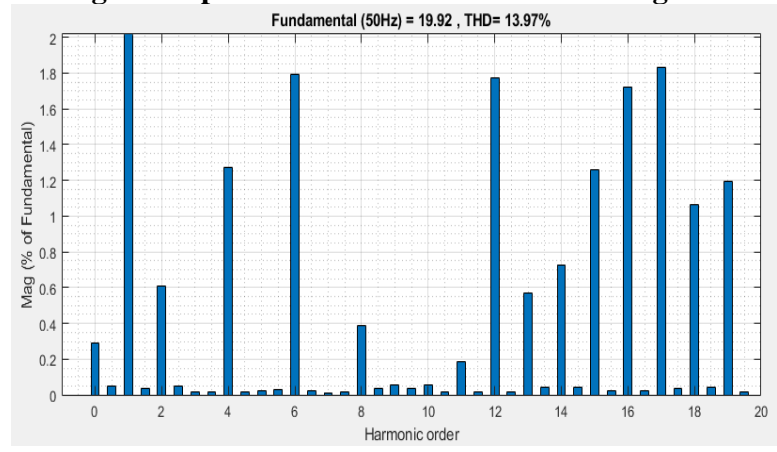

Fig 7: THD of Output Waveform of Nine-levels.

\section{CONCLUSION}

A simulation model of 9-level asymmetric cascaded Developed H-bridge with Half -bridge MLI has been modelled by eight power switches (IGBTs) with three sources of DC power. The FFT analysis of output voltage waveform is carried out at 19.92 and THD is found to be $13.97 \%$. This Modified MLI can be interfacing with renewable energy sources such as PV cells and wind power It can be extended for motor drives, electric vehicle drives, power factor compensators and DC power source utilization. This Modified MLI chosen as the best option in the field of power industry, and reactive power compensation. 


\section{ACKNOWLEDGEMENT}

I pay my heartfelt gratitude to my supervisor Prof. Dr. Mukhtiar Ahmed Mahar and my co-supervisor Dr. Sohail Khokhar for their support and encouragement for the completion of this research.

\section{REFERENCES}

[1] E. B. a. G. B. G. J. Ebrahimi, "A new topology of cascaded multilevel converters with reduced number of components for high-voltage applications," in IEEE Trans. Power Electron, november 2011.

[2] R. S. A. N. S. S. H. H. E. B. Jagabar Sathik Mohamed Ali, "A new generalized multilevel converter topology based on cascaded connection of basic units," IEEE Journal of Emerging and Selected Topics in Power Electronics, vol. 7, no. 4, pp. 2498-2512, 2019.

[3] E. B. a. S. H. Hosseini, "Charge balance control methods for asymmetrical cascade multilevel converters," in International Conference on Electrical Machines and Systems (ICEMS), 2007.

[4] H. D. S. G. S. S. H. a. R. H. Vemuganti, "A Survey on Reduced Switch Count Multilevel Inverters.," IEEE Open Journal of the Industrial Electronics Society, vol. 55, 2021.

[5] M. A. M. A. U. a. A. S. L. Mahar, "Harmonic analysis of ac-dc topologies and their impacts on power systems.," Mehran University Research Journal of Engineering \& Technology, vol. 1, pp. 173-178, 2011.

[6] M. A. F. N. a. A. I. Ali Mostafaeipour, "Identifying challenges and barriers for development of solar energy by using fuzzy best-worst method: A case study," Energy, vol. 226, 2021.

[7] S. A. a. S. L. Ebrahim Babaei, "A New General Topology for Cascaded Multilevel Inverters With
Reduced," IEEE TRANSACTIONS ON INDUSTRIAL ELECTRONICS,, vol. 61, 2014.

[8] A. H. A. S. L. M. A. M. A. A. S. I. A. S. Soomro, "Simulation-based Analysis of a Dynamic Voltage Restorer under Different Voltage Sags with the Utilization of a PI Controller," Engineering, Technology \& Applied Science, vol. 4, pp. 5889-5895, 2020.

[9] N. P. K. Prabaharan, "Comparative analysis of symmetric and asymmetric reduced switch MLI topologies using unipolar pulse width modulation strategies," IET Power Electron.,, vol. 15, pp. 2808-2823, 2016.

[10] M. R. M. A. M. a. A. S. L. Qureshi, "Harmonic Analysis and Design of LC Filter for a Seven-level Asymmetric Cascaded Half Bridge Multilevel Inverter.," International Journal of Electrical Engineering \& Emerging Technology, vol. 2, no. 3, pp. 52-58, 2020.

[11] J. I. S. V. a. L. G. F. Leon, "Multilevel converters: Control and modulation techniques for their operation and industrial applications," Proceedings of the IEEE, , vol. 105, no. 11, pp. 2066-2081, 2017.

[12] M. B. E. Kangarlu, "'A generalized cascaded multilevel inverter using series connection of sub-multilevel inverters," IEEE Trans. Power Electron, vol. 28, pp. 625635, 2013.

[13] T. A. R. V. S. a. J. B. P. G. A. Ramesh Babu, "Novel cascaded H-bridge sub-multilevel inverter with reduced switches towards low total harmonic distortion for photovoltaic application," International Journal of Ambient Energy, vol. 39, no. 2, pp. 117-121, 2018.

[14] I. K. E. B. R. c- Colak, "Review of multilevel voltage source," Energy Convers. Manage, vol. 52, p. 1114$1128,2011$. 